\title{
Natural course of early COPD
}

This article was published in the following Dove Press journal:

International Journal of COPD

20 February 2017

Number of times this article has been viewed

\author{
Chin Kook Rhee,' Kyungjoo \\ Kim,' Hyoung Kyu Yoon, ${ }^{2}$ \\ Jee-Ae Kim, ${ }^{3}$ Sang Hyun \\ Kim, ${ }^{4}$ Sang Haak Lee, ${ }^{5}$ Yong \\ Bum Park, ${ }^{6}$ Ki-Suck Jung, ${ }^{7}$ \\ Kwang $\mathrm{Ha} \mathrm{Yoo,}{ }^{8}$ Yong II \\ $\mathrm{Hwang}^{7}$
}

'Division of Pulmonary, Allergy and Critical Care Medicine, Department of Internal Medicine, Seoul St Mary's Hospital, ${ }^{2}$ Division of Pulmonary and Critical Care Medicine, Department of Internal Medicine, Yeouido

St Mary's Hospital, College of Medicine, The Catholic University of Korea, Seoul, ${ }^{3}$ Pharmaceutical Policy Evaluation Research Team, Research Institution, ${ }^{4} \mathrm{Big}$ Data Division, Health Insurance Review and Assessment Service, Wonju, ${ }^{5}$ Division of Pulmonary, Critical Care and Sleep Medicine, Department of Internal Medicine, St Paul's Hospital, College of Medicine, The Catholic University of Korea, ${ }^{6}$ Division of Pulmonary, Allergy, and Critical Care Medicine, Department of Internal Medicine, Hallym University Kangdong Sacred Heart Hospital, Seoul, ${ }^{7}$ Division of Pulmonary, Allergy and Critical Care Medicine, Department of Internal Medicine, Hallym University Sacred Heart Hospital, Hallym University College of Medicine, Anyang, ${ }^{8}$ Division of Pulmonary, Allergy and Critical Care Medicine, Department of Internal Medicine, Konkuk University School of Medicine, Seoul, Republic of Korea

Correspondence: Yong II Hwang Division of Pulmonary, Allergy and Critical Care Medicine, Department of Internal Medicine, Hallym University Sacred Heart Hospital, Hallym University College of Medicine, 896 Pyeongandong, Dongan-gu, Anyang 43I-070, Gyeonggi-do, Republic of Korea

Tel +82313803715

Fax +82313803973

Email hyicyk@hallym.or.kr
Background and objective: Few studies have examined the natural course of early COPD. The aim of this study was to observe the natural course of early COPD patients. We also aimed to analyze medical utilization and costs for early COPD during a 6-year period.

Methods: Patients with early COPD were selected from Korean National Health and Nutrition Examination Survey (KNHANES) data. We linked the KNHANES data of patients with early COPD to National Health Insurance data.

Results: A total of 2,397 patients were enrolled between 2007 and 2012. The mean forced expiratory volume in 1 second $\left(\mathrm{FEV}_{1}\right)$ was $78.6 \%$, and the EuroQol five dimensions questionnaire (EQ-5D) index value was 0.9. In total, 110 patients utilized health care for COPD in 2007, and this number increased to 179 in 2012. The total mean number of days used per person increased from 4.9 in 2007 to 7.8 in 2012 . The total medical cost per person also increased from 248.8 US dollar (USD) in 2007 to 780.6 USD in 2013. A multiple linear regression revealed that age, lower body mass index, lower $\mathrm{FEV}_{1}(\%)$, and lower EQ-5D score were significantly associated with medical costs.

Conclusion: Even in early COPD patients, some of them eventually progressed and utilized health care for COPD.

Keywords: early COPD, KNHANES, NHI, HIRA, utilization, cost

\section{Introduction}

COPD is a leading cause of death worldwide and contributes to social and economic burden. ${ }^{1}$ However, there are still many undiagnosed patients with COPD worldwide. One of the main reasons for this is that there are few respiratory symptoms in early COPD patients. ${ }^{2}$ Sometimes, patients consider their COPD symptoms as part of the normal aging process but not as pathological changes. Moreover, a pulmonary function test (PFT) is not routinely performed in populations at high risk of COPD. ${ }^{3}$

The so-called early COPD is expected to eventually develop into symptomatic COPD. ${ }^{4}$ However, few studies have investigated the natural course of patients with early COPD, ${ }^{5}$ primarily because undiagnosed early COPD patients usually do not visit the hospital. Thus, routine follow-up of these early COPD patients is extremely difficult. Moreover, long-term follow-up and observation of the natural course of early COPD are almost impossible.

Although these early COPD patients have mild symptoms and relatively good lung function, it is important to identify and manage these patients. The decline in forced expiratory volume in 1 second $\left(\mathrm{FEV}_{1}\right)$ was higher in Global Initiative for Chronic Obstructive Lung Disease (GOLD) stage I and II patients compared with stage III and IV patients. ${ }^{6}$ Even patients with early COPD have pathological changes, ${ }^{7}$ physiological changes, ${ }^{8}$ more systemic inflammation, ${ }^{9}$ and more comorbidities. ${ }^{10}$

The Korean National Health and Nutrition Examination Survey (KNHANES) is performed annually in Korea. The Korean Academy of Tuberculosis and Respiratory 
Diseases and the Korea Centers for Disease Control and Prevention (KCDC) began conducting national health and nutrition surveys, including an assessment of COPD prevalence, in 2007. Spirometry was performed as part of the survey, and many patients with mild, early COPD were identified by the KNHANES. According to the report of KNHANES 2008 by Yoo et al, ${ }^{11}$ most cases of COPD diagnosed by the KNHANES were mild and asymptomatic. In all, $94 \%$ of patients had GOLD stage I or II. Only $2.4 \%$ of patients were reported having been diagnosed with COPD by a physician before KNHANES, and 2.1\% were reported having been treated for COPD. Thus, COPD patients identified by the KNHANES are an excellent sample of early COPD patients.

South Korea has a compulsory universal health insurance system that includes medical reimbursement records for the entire Korean population. The National Health Insurance (NHI) reimbursement database provides a unique and advantageous mechanism for evaluating the nationwide magnitude of an illness and consequent health care use. ${ }^{12-15}$ The follow-up of patients with early COPD identified by the KNHANES was extremely difficult, as they rarely visited the hospital even after their diagnosis of COPD by the KNHANES. Because lung function is relatively good and symptoms are mild, there is little motivation for them to see a physician and follow up regularly. However, by using the NHI database, it is possible to trace every single detail of medical utilization and costs for early COPD patients. Thus, we merged the KNHANES and NHI data of patients with early COPD to investigate the natural course of early COPD.

In this study, we aimed to observe the natural course of early COPD patients. We also aimed to analyze the medical utilization and costs for early COPD during a 6-year period.

\section{Methods}

\section{Study design}

Patients with early COPD were selected from the KNHANES (2007-2012) database. The inclusion criteria for early COPD were: 1) age $\geq 40$ years; 2) $\mathrm{FEV}_{1}$ /forced vital capacity (FVC) $<0.7$; and 3 ) $\mathrm{FEV}_{1} \geq 50 \%$. The KNHANES data of patients with early COPD and their NHI data were linked by the KCDC and Health Insurance Review and Assessment Service (HIRA). The personal identification of all patients was blinded to the researchers, and the merged data lacking any personal identification information were delivered to the researchers.
Baseline characteristics, including age, sex, body mass index (BMI), income, smoking history, lung function, and the EuroQol five dimensions questionnaire (EQ-5D) score, were obtained from the KNHANES data.

Medical utilization and costs from the NHI data were analyzed. The analysis was restricted to COPD-related utilization and costs over the 6 years; any medical utilization or costs not related to COPD were excluded. For outpatient services, analysis was confined to visits with the International Classification of Diseases, Tenth Edition (ICD-10) code of COPD (J43.X-J44.x, except J430) with prescription of COPD-related medication. For inpatient services, analysis was confined to admission with ICD-10 code of COPD (J43.X-J44.X, except J430) or COPD-related diseases (pneumonia: J12.X-J17.x; pulmonary thromboembolism: I26, I26.0, and I26.9; dyspnea: R06.0; or acute respiratory distress syndrome: J80).

Information on COPD medication was also analyzed by NHI data. Prescriptions of long-acting muscarinic antagonist (LAMA), long-acting beta-2 agonist (LABA), inhaled corticosteroid (ICS), inhaled corticosteroid plus long-acting beta-2 agonist (ICS + LABA), short-acting muscarinic antagonist (SAMA), short-acting beta-2 agonist (SABA), short-acting muscarinic antagonist plus short-acting beta-2 agonist (SAMA + SABA), methylxanthine, systemic bronchodilator, oral corticosteroid (OCS), and intravenous corticosteroid (IVCS) were analyzed.

All costs were presented in US dollar (USD) with an exchange rate of $1 \mathrm{USD}=1,140$ Korean Won (exchange rate as on April 29, 2016).

This study was approved by the ethics committee of Konkuk University Hospital. The requirement for informed consent from the patients was waived due to the retrospective nature of this study.

\section{Statistical analysis}

Differences between groups were assessed using the chisquare test for categorical variables and Student's $t$-test for continuous variables. Multiple linear regression analysis was performed to identify factors affecting medical costs. The dependent variable was log transformed for the linear regression analysis, as health care utilization variables are usually right skewed (ie, distributed with a long and heavy right tail). All tests were two sided, and $P$-values $<0.05$ were considered statistically significant. Data are expressed as mean \pm standard deviation. All statistical analyses were performed using SAS version 9.2 software (SAS Institute Inc., Cary, NC, USA). 


\section{Results}

\section{Baseline characteristics}

The total number of people in the KNHANES database between 2007 and 2012 was 50,405. There were 22,926 (45.5\%) males and 27,479 (54.55\%) females. Among these patients, a total of 2,397 patients (1,692 males [70.6\%] and 705 females [29.4\%]; mean age 63.5 years) were enrolled in this study. The mean BMI was $23.5 \pm 2.9 \mathrm{~kg} / \mathrm{m}^{2}$, and 1,621 patients $(67.6 \%)$ were current or ex-smokers. The mean $\mathrm{FEV}_{1} / \mathrm{FVC}$ ratio was $60.0 \%$, and the mean $\mathrm{FEV}_{1}$ was $2.3 \mathrm{~L}$ (78.6\% of predicted). Approximately 45\% $(1,075 / 2,397)$ of patients had mild airflow limitations $\left(\mathrm{FEV}_{1} \geq 80 \%\right.$ of predicted) and 55.2\% $(1,322 / 2,397)$ had moderate airflow limitations ( $50 \% \leq \mathrm{FEV}_{1} \%<80 \%$ of predicted). The mean EQ-5D index value was 0.9 (Table 1).

\section{Health care utilization}

A total of 110 patients utilized health care for COPD in 2007, and this number increased to 179 in 2012. The number of outpatients and inpatients increased over time (Figures 1 and 2). The total mean number of days used per person increased

Table I Baseline characteristics $(n=2,397)$

\begin{tabular}{ll}
\hline Characteristics & $\mathbf{n}(\%)$ or mean \pm SD \\
\hline Male & $1,692(70.6)$ \\
Age (years) & $63.5 \pm 11.9$ \\
$\quad<50$ & $298(12.4)$ \\
$50-59$ & $448(18.7)$ \\
$60-69$ & $804(33.5)$ \\
$70-79$ & $743(31.0)$ \\
$\geq 80$ & $104(4.3)$ \\
BMI, kg/m² & $23.5 \pm 2.9$ \\
Income/month (USD) & $2,458.8 \pm 10,154.0$ \\
Smoking & \\
Current & $757(31.6)$ \\
Ex & $864(36.0)$ \\
Never & $747(31.2)$ \\
Unknown & $29(1.2)$ \\
Pack years & $23.9 \pm 23.3$ \\
FVC (L) & $3.6 \pm 0.9$ \\
FVC (\%) & $90.9 \pm 13.6$ \\
FEV (L) & $2.3 \pm 0.6$ \\
FEV $(\%)$ & $78.6 \pm 13.6$ \\
GOLD I & $1,075(44.8)$ \\
GOLD 2 & $1,322(55.2)$ \\
FEV /FVC & $0.6 \pm 0.1$ \\
EQ-5D & $0.9 \pm 0.1$ \\
EQ-5D $\geq 0.9$ & $1,611(67.2)$ \\
\hline Abbreiaton &
\end{tabular}

Abbreviations: SD, standard deviation; BMI, body mass index; USD, US dollar; FVC, forced vital capacity; $F E V_{1}$, forced expiratory volume in I second; GOLD, Global Initiative for Chronic Obstructive Lung Disease; EQ-5D, EuroQol five dimensions questionnaire.

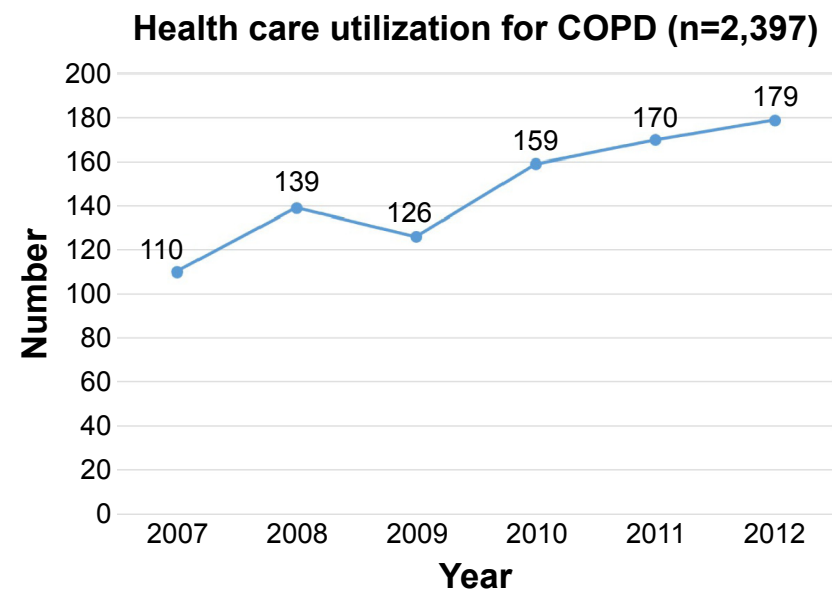

Figure I Number of patients with health care utilization for COPD.

from 4.9 in 2007 to 7.8 in 2012. The total medical cost per person also increased from 248.8 USD in 2007 to 780.6 USD in 2013 (Figure 3).

The number of patients who visited the emergency room (ER) and/or hospitalized due to COPD increased. Four patients visited the ER (not hospitalized) in 2007, and this number increased to 12 in 2013. A total of 13 patients were hospitalized (including admission via the ER) in 2007, and this number increased to 33 in 2013 (Table 2).

\section{Medication use}

The most frequently prescribed medication in 2007 was methylxanthine (57.3\%), followed by a systemic bronchodilator (37.3\%). The ICS + LABA and LAMA prescription rates were $15.5 \%$ and $10.9 \%$, respectively, in 2007 . However, although methylxanthine remained the number one prescribed medication (51.4\%) in 2013, LAMA and ICS + LABA were the second-most prescribed medications (24.6\% and $24.6 \%$, respectively). In contrast, the frequency of systemic bronchodilator prescriptions was

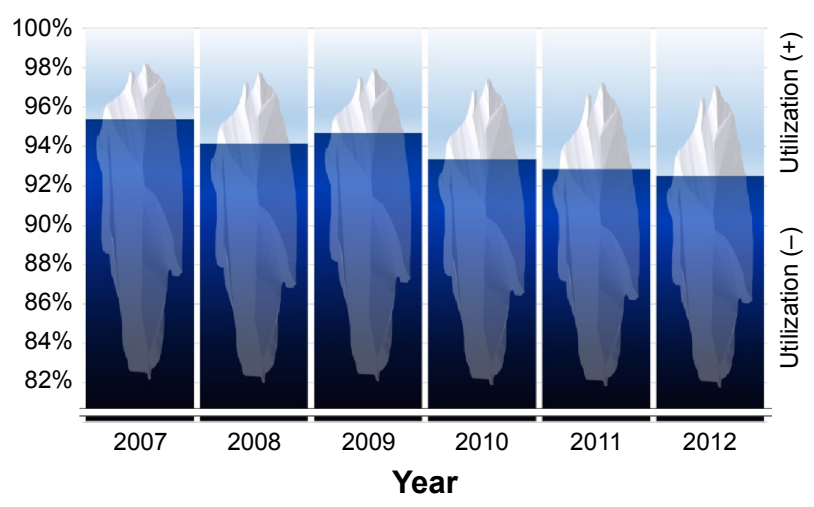

Figure 2 Percentage of patients with health care utilization for early COPD. 


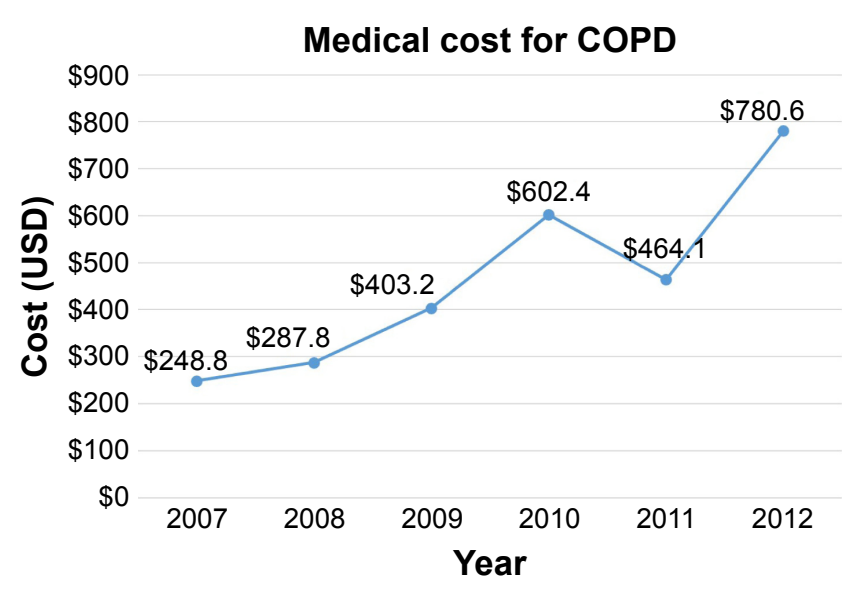

Figure 3 Mean medical cost for COPD per person.

Notes: Only patients with health care utilization for COPD were analyzed. Patients without utilization were excluded from analysis.

Abbreviation: USD, US dollar.

less than that for LAMA or ICS + LABA (24.0\%; Figure 4 and Table 3).

\section{Factors affecting medical costs}

A multiple linear regression was performed to identify the factors affecting medical costs. Age, sex, BMI, income, smoking status, $\mathrm{FEV}_{1}(\%)$, and EQ-5D score were used for analysis. Among them, older age, lower BMI, lower $\mathrm{FEV}_{1}(\%)$, and lower EQ-5D score were significantly associated with medical costs (Table 4).

\section{Discussion}

Until now, little has been understood regarding patients with early COPD. Moreover, the natural course of patients with early COPD has not been reported. In this 6-year follow-up study, some of the patients with early COPD eventually utilized health care for their COPD. Among the 2,397 patients with early COPD, only 110 utilized health care for COPD in 2007. However, this number increased annually, and eventually, 170 patients had utilized health care for their
COPD 6 years later. Likewise, mean medical costs per person increased in these populations. Also, the number of hospitalized patients increased from 13 to 33 over the 6-year period. These findings suggest that even in early COPD patients, some of them eventually progressed and utilized health care for COPD. Moreover, some of them even exacerbated and were admitted to the hospital. Interestingly, several factors were associated with increased medical costs in early COPD patients. Old age, low BMI, low FEV ${ }_{1}$, and low EQ-5D score were significant factors. Thus, we can postulate that early COPD patients with these risk factors may progress and utilize health care for COPD.

The other interesting finding in this study is that even though some early COPD patients progressed and utilized health care, the other majority of patients still did not utilize health care. We are not sure if the number of patients who utilize health care would increase if the follow-up period was extended (eg, to $>10$ years). However, during the 6-year follow-up, the annual percentage of patients who utilized health care for COPD was $<10 \%$.

It is also very interesting to note that there was an evident change in the medication pattern. In 2007, the prescription rate of inhaler was very low. After 6 years, even though it was still low, the inhaler use increased. This also suggests that some of early COPD patients may progress and become symptomatic during the 6-year follow-up.

This study is valuable in many aspects. First, we demonstrated for the first time the natural clinical course of a large number of early COPD patients. To our best knowledge, this is the first large-scale $(n=2,397)$ report regarding patients with early COPD. Second, we tracked all of their medical utilization and costs for 6 years without any missing data. This was possible because of the unique nature of the Korean medical system. All Koreans are covered by the national insurance system, which is mandatory by law. The HIRA data can provide very accurate information regarding medical

Table 2 Health care utilization by early COPD patients

\begin{tabular}{|c|c|c|c|c|c|c|}
\hline & $2007(n=\mid 10)$ & $2008(n=139)$ & $2009(n=126)$ & $2010(n=159)$ & $2011(n=170)$ & $2012(n=179)$ \\
\hline OPD visit, n (\%) & $103(99.0)$ & $133(95.7)$ & $121(96.0)$ & I 47 (92.5) & $162(95.3)$ & I64 (9l.6) \\
\hline $\begin{array}{l}\text { No of OPD visit, } \\
\text { mean } \pm S D\end{array}$ & $4.0 \pm 5.2$ & $4.2 \pm 4.7$ & $4.5 \pm 5.3$ & $4.6 \pm 4.7$ & $4.8 \pm 8.5$ & $4.9 \pm 5.2$ \\
\hline ER visit, n (\%) & $4(3.8)$ & $7(5.0)$ & $4(3.2)$ & $7(4.4)$ & $9(5.3)$ & $12(6.7)$ \\
\hline Hospitalization, n (\%) & $13(12.5)$ & $14(10.1)$ & $12(9.5)$ & $22(13.8)$ & $22(12.9)$ & $33(18.4)$ \\
\hline ICU, n (\%) & $2(1.9)$ & I (0.7) & $2(1.6)$ & $3(1.9)$ & $4(2.4)$ & $5(2.8)$ \\
\hline $\begin{array}{l}\text { Total used days, } \\
\text { mean } \pm \text { SD }\end{array}$ & $4.9 \pm 6.0$ & $5.5 \pm 7.7$ & $6.0 \pm 8.7$ & $6.8 \pm 10.1$ & $6.7 \pm 11.0$ & $7.8 \pm 11.6$ \\
\hline $\begin{array}{l}\text { Cost/year (USD), } \\
\text { mean } \pm \text { SD }\end{array}$ & $248.8 \pm 626.7$ & $287.8 \pm 797.3$ & $403.2 \pm 1,392.7$ & $602.4 \pm 2,102.7$ & $464.1 \pm I, 358.2$ & $780.6 \pm 2,606.3$ \\
\hline
\end{tabular}

Abbreviations: OPD, outpatient department; SD, standard deviation; ER, emergency room; ICU, intensive care unit; USD, US dollar. 


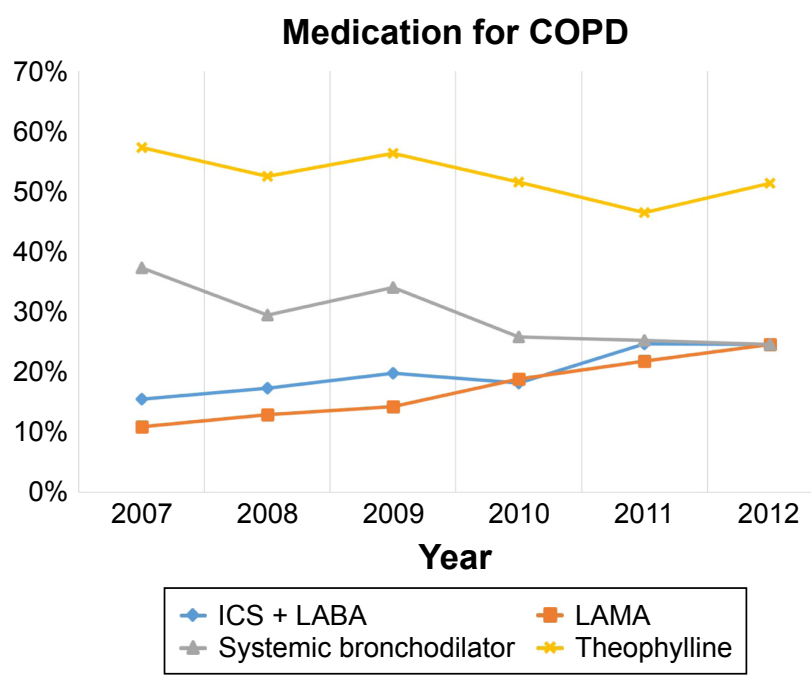

Figure 4 Changes in the medication for COPD.

Abbreviations: ICS + LABA, inhaled corticosteroid plus long-acting beta- 2 agonist; LAMA, long-acting muscarinic antagonist.

utilization and costs. Third, this study showed nationwide real-world phenomenon. This was not an interventional study but a retrospective study without any missing data. Thus, we could observe how early COPD patients acted and how their disease progressed without any bias. This real-world result is hard to be replicated in other study because it is almost impossible for such early COPD patients enrolled in this study to be enrolled in another cohort or interventional study. This study will provide precious important information for future studies on early COPD. Fourth, this study contains many information that would have been missed in other claim data. Usually, claim data do not provide important information, such as lung function, smoking status, or quality of life. This is not an exception in HIRA data. However, by combining the HIRA data to KNHANES data, we have created a valuable dataset that includes lung function, smoking status, and quality of life.

Until now, there has been no evidence whether a physician identifies and treats early COPD patients. However, we clearly showed that some of early COPD patients progressed and utilized health care for COPD. Moreover, we also demonstrated that some of them even exacerbated. Our study can provide rationale for early diagnosis and treatment of early COPD patients. Specifically, patients with risk factors (old age, lower BMI, lower FEV 1 (\%), and lower EQ-5D) should be managed more aggressively. Intervention to stop smoking should be provided, and early pulmonary rehabilitation can be also considered. Moreover, medication that showed beneficial effect to slow decline of $\mathrm{FEV}_{1}$ also needs to be prescribed to these patients.

There are several limitations in this study. First, this is a retrospective study. However, unlike other studies, we have collected all the information regarding medical utilization and costs for health care. This would have been impossible if we did not use the HIRA dataset. Second, the PFT results in this study are prebronchodilator ones. However, in many large epidemiologic studies, the PFT results were also usually prebronchodilator ones. Studies regarding COPD by using large epidemiologic data also showed only prebronchodilator PFT results. For example, the prebronchodilator value from Copenhagen City Heart Study and Lovelace Smokers Cohort was used in the study of Lange et al. ${ }^{16}$ Also, in the report by Mannino et al, ${ }^{17}$ the prebronchodilator value from Atherosclerosis Risk in Communities Study and Cardiovascular Health Study was used. This is because performing post-bronchodilator PFTs in a large scale is extremely difficult. In KNAHNES, post-bronchodilator PFTs were not performed because of safety concerns. Third, we could not follow PFT and EQ-5D in this study. It would be ideal if we had followed changes in lung function, quality of life, and progression of emphysema. However, unfortunately, it was not possible in our dataset.

\section{Conclusion}

We reported the natural course of early COPD patients by combining KNAHANES and HIRA data. Although medical

Table 3 Medication prescribed in early COPD

\begin{tabular}{|c|c|c|c|c|c|c|}
\hline & $2007(n=110)$ & $2008(n=139)$ & $2009(n=126)$ & $2010(n=159)$ & $2011(n=170)$ & $2012(n=179)$ \\
\hline ICS, n (\%) & $7(6.4)$ & $5(3.6)$ & $10(7.9)$ & $8(5.0)$ & $7(4.1)$ & $15(8.4)$ \\
\hline ICS + LABA, n (\%) & $17(15.5)$ & $24(17.3)$ & $25(19.8)$ & $29(18.2)$ & $42(24.7)$ & $44(24.6)$ \\
\hline LAMA, n (\%) & $12(10.9)$ & $18(12.9)$ & $18(14.3)$ & $30(18.9)$ & $37(21.8)$ & $44(24.6)$ \\
\hline SAMA, n (\%) & $12(10.9)$ & $6(4.3)$ & $10(7.9)$ & II (6.9) & $9(5.3)$ & $13(7.3)$ \\
\hline SABA, n (\%) & $20(18.2)$ & $18(12.9)$ & $18(14.3)$ & $26(16.4)$ & $25(14.7)$ & $44(24.6)$ \\
\hline Systemic bronchodilator, n (\%) & $4 \mid(37.3)$ & 4 I (29.5) & $43(34.1)$ & $4 \mathrm{I}(25.8)$ & $43(25.3)$ & $43(24.0)$ \\
\hline Methylxanthine, n (\%) & $63(57.3)$ & $73(52.5)$ & $71(56.3)$ & $82(51.6)$ & $79(46.5)$ & $92(51.4)$ \\
\hline
\end{tabular}

Abbreviations: ICS, inhaled corticosteroid; ICS + LABA, inhaled corticosteroid plus long-acting beta-2 agonist; LAMA, long-acting muscarinic antagonist; SAMA, short-acting muscarinic antagonist; SABA, short-acting beta-2 agonist. 
Table 4 Factors associated with increased medical costs in early COPD patients

\begin{tabular}{llllll}
\hline Variable & \multicolumn{2}{l}{ Unadjusted } & & \multicolumn{2}{l}{ Adjusted } \\
\cline { 2 - 3 } & $\boldsymbol{\beta}$ & $\boldsymbol{P}$-value & & $\beta$ & $\boldsymbol{P}$-value \\
\hline Male sex & 72 & 0.122 & & 94 & 0.063 \\
Age & 7 & $<0.001$ & & 7 & $<0.00 \mathrm{I}$ \\
BMI, kg/m & -19 & 0.012 & & -18 & 0.015 \\
Income & -11 & 0.609 & & -7 & 0.734 \\
Current smoker & 31 & 0.503 & & 23 & 0.646 \\
FEV (\%) & -5 & 0.002 & & -6 & $<0.001$ \\
EQ-5D & -519 & $<0.001$ & & -445 & 0.005 \\
\hline
\end{tabular}

Abbreviations: $\mathrm{BMI}$, body mass index; $\mathrm{FEV}_{1}$, forced expiratory volume in I second; EQ-5D, EuroQol five dimensions questionnaire.

utilization and costs for COPD were low in this population, they increased over time. Age, lower BMI, lower FEV (\%), and lower EQ-5D score were significantly associated with medical costs. A further study regarding early COPD is needed.

\section{Acknowledgments}

This study was supported by a grant (2014P3300300) from the Korea Centers for Disease Control and Prevention. This study was supported by COPD cohort data of HIRA.

\section{Disclosure}

CKR received consulting/lecture fees from MSD, AstraZeneca, Novartis, GSK, Takeda, Mundipharma, Sandoz, Boehringer-Ingelheim, and Teva-Handok. The other authors report no conflicts of interest in this work.

\section{References}

1. Global strategy for the diagnosis, management, and prevention of chronic obstructive pulmonary disease. 2016. Available from: http://goldcopd. org/global-strategy-diagnosis-management-prevention-copd-2016/. Accessed October 15, 2016.

2. Antonelli-Incalzi R, Imperiale $\mathrm{C}$, Bellia V, et al; SaRA Investigators. Do GOLD stages of COPD severity really correspond to differences in health status? Eur Respir J. 2003;22(3):444-449.
3. Guirguis-Blake JM, Senger CA, Webber EM, Mularski RA, Whitlock EP. Screening for chronic obstructive pulmonary disease: evidence report and systematic review for the US preventive services task force. JAMA. 2016; 315(13):1378-1393.

4. Decramer M, Cooper CB. Treatment of COPD: the sooner the better? Thorax. 2010;65(9):837-841.

5. Rennard SI, Drummond MB. Early chronic obstructive pulmonary disease: definition, assessment, and prevention. Lancet. 2015;385(9979): $1778-1788$.

6. Tantucci C, Modina D. Lung function decline in COPD. Int J Chron Obstruct Pulmon Dis. 2012;7:95-99.

7. Hogg JC, Chu F, Utokaparch S, et al. The nature of small-airway obstruction in chronic obstructive pulmonary disease. N Engl J Med. 2004; 350(26):2645-2653.

8. Rodriguez-Roisin R, Drakulovic M, Rodriguez DA, Roca J, Barbera JA, Wagner PD. Ventilation-perfusion imbalance and chronic obstructive pulmonary disease staging severity. J Appl Physiol (1985). 2009; 106(6):1902-1908.

9. Agusti A, Edwards LD, Rennard SI, et al; Evaluation of COPD Longitudinally to Identify Predictive Surrogate Endpoints (ECLIPSE) Investigators. Persistent systemic inflammation is associated with poor clinical outcomes in COPD: a novel phenotype. PLoS One. 2012;7(5): e37483.

10. Van Remoortel H, Hornikx M, Langer D, et al. Risk factors and comorbidities in the preclinical stages of chronic obstructive pulmonary disease. Am J Respir Crit Care Med. 2014;189(1):30-38.

11. Yoo KH, Kim YS, Sheen SS, et al. Prevalence of chronic obstructive pulmonary disease in Korea: the fourth Korean National Health and Nutrition Examination Survey, 2008. Respirology. 2011; 16(4):659-665.

12. Kim C, Yoo KH, Rhee CK, et al. Health care use and economic burden of patients with diagnosed chronic obstructive pulmonary disease in Korea. Int J Tuberc Lung Dis. 2014;18(6):737-743.

13. Kim J, Lee JH, Kim Y, et al. Association between chronic obstructive pulmonary disease and gastroesophageal reflux disease: a national cross-sectional cohort study. BMC Pulm Med. 2013;13:51.

14. Kim J, Rhee CK, Yoo KH, et al. The health care burden of high grade chronic obstructive pulmonary disease in Korea: analysis of the Korean Health Insurance Review and Assessment Service data. Int J Chron Obstruct Pulmon Dis. 2013;8:561-568.

15. Rhee CK, Yoon HK, Yoo KH, et al. Medical utilization and cost in patients with overlap syndrome of chronic obstructive pulmonary disease and asthma. COPD. 2014;11(2):163-170.

16. Lange P, Celli B, Agusti A, et al. Lung-function trajectories leading to chronic obstructive pulmonary disease. N Engl J Med. 2015;373(2): $111-122$.

17. Mannino DM, Thorn D, Swensen A, Holguin F. Prevalence and outcomes of diabetes, hypertension and cardiovascular disease in COPD. Eur Respir J. 2008;32(4):962-969.
International Journal of COPD

\section{Publish your work in this journal}

The International Journal of COPD is an international, peer-reviewed journal of therapeutics and pharmacology focusing on concise rapid reporting of clinical studies and reviews in COPD. Special focus is given to the pathophysiological processes underlying the disease, intervention programs, patient focused education, and self management protocols.

\section{Dovepress}

This journal is indexed on PubMed Central, MedLine and CAS. The manuscript management system is completely online and includes a very quick and fair peer-review system, which is all easy to use. Visit $\mathrm{http}: / / \mathrm{www}$.dovepress.com/testimonials.php to read real quotes from published authors. 